\title{
ECO-ENVIRONMENTAL VULNERABILITY ZONATION IN ESSENCE OF ENVIRONMENTAL MONITORING AND MANAGEMENT
}

\author{
R. Venkatesh ${ }^{1, *}$, S. Abdul Rahaman ${ }^{2}$, R. Jegankumar ${ }^{3}$, P.Masilamani ${ }^{4}$ \\ Department of Geography, Bharathidasan University, Tiruchirappalli, Tamil Nadu, India. \\ (1'venkatvejef007@gamil.com, ${ }^{2}$ abdulatgeo@gmail.com, ${ }^{3}$ jegankumar@bdu.ac.in, ${ }^{4}$ masilamani.ap@gmail.com)
}

Commission V, Youth Forum

KEY WORDS: Eco-environment, AHP, Geospatial technology, Vulnerability, Management, Sustainable development.

\begin{abstract}
:
The concern of present-day conservation of eco-environment and its approach is to diminish the vulnerability, which demands focus region identification and protection. The identification of the focus region needs greater expertise and management. However, assessment of eco-environmental vulnerability requires numerous variables. The variables are categorised under four extensive aspects namely, hydro-meteorology, land resources, topography and socio-economic factors. The Pombar watershed enfolds three main urbanised cities Bargur, Thirupattur and Uthangarai connected by state-highway (SH-179A) and most of the settlements are situated near foothill regions. Thus, the cultural features persisting in the watershed are subjected to eco-environment vulnerable conditions. Therefore, extraction of variables is carried out using Landsat 8 OLI, Sentinel-2B, ALOS PALSAR DEM and IMD rainguage data respectively. The generated parameters affecting the environment are weighed and ranked through the Analytical Hierarchical Process (AHP) with Geospatial technology for eco-environment vulnerability assessment. Then vulnerability level is categorised into five classes like very high, high, moderate, low and very low with an area of $10 \%, 12 \%, 37 \%, 23 \%$, and $18 \%$ respectively. The very high and high classes are distributed in low lying plain regions, where there is high anthropogenic activities, urbanisation and industrialisation, a moderate vulnerable class is more in plateau region due to deforestation and over exploitation. However, very low and low classes are sparsely distributed in higher altitude. The integration of Geospatial technology with AHP makes a powerful tool to assess the eco-environment vulnerability and therefore, three focus regions are demarcated to devote a massive concern on protection and management in the essence of sustainable development.
\end{abstract}

\section{ECO-ENVIRONMENTAL VULNERABILTY ASSSESSMENT}

\subsection{Introduction}

Hazard and disaster are indispensable issues that act as a threat to humans and their surroundings. It is persistent for a long time with very little knowledge; planning and execution, which is detected throughout the spatial and temporal scale around the world. The pattern of its incidences has increased manifold in frequency. In a similar way, an environmental hazard is a prominent threat in the study area. Pombar Watershed is a significant region for socio-economic development and urbanisation. The watershed is frequently affected by trade and migration activities, as it is positioned in north-eastern region of Tamil Nadu, a border between two states, as development increase with prompting to environment degradation. Nowadays anthropogenic activities are predominant in the watershed regions. Then the level of environment declining is increased day by day and ecological balance is distributed. Thus, the study area deserves an assessment of eco-environmental vulnerability. In order to evaluate the eco-environmental vulnerability, four factors of hydro-meteorological, topographical, socioeconomical, land resources are considered as governing parameters. Those four factors are separately extracted and analysed with their 12 sub factors. And the combined influence of four factors segregates the vulnerable zones. Since 1960, the environmental impact assessment came into use (Weston, 2004; Wang et al., 2008), then ecological and environmental impact and vulnerability assessment evolved later to estimate the quantitative level of degradation and condition of eco- environment with the help of Remote Sensing (RS) and Geographic Information System (GIS) (Store and Jokima"ki, 2003; Krivtsov, 2004; MacMillan et al., 2004; Wang et al., 2008). Where RS and GIS are substantial tools in the field of geographical and environmental sciences such as land degradation (El Baroudy, 2011), ecological impact assessment (Guebas, 2002; Rigina, 2002), soil erosion (Bahadur, 2009; Pradhan, 2012; Nitheshnirmal et al., 2019) drought (Belal, 2014; Dutta, 2015), monitoring of landscape changes (Gustafson et al., 2005) and eco-environmental vulnerability (Nguyen et al., 2016; Liou et al., 2017). For eco-environmental vulnerability assessment on a regional scale, it is essential to pinpoint the vulnerable location, in order to protect the remaining resources and rejuvenate the declining resources with a suitable management and planning technique. There are numerous methods to estimate eco-environmental vulnerability, such as comprehensive evaluation (Goda and Matsuoka, 1986), Analytic Hierarchy Process (AHP) (Song et al., 2010; Thanh and De Smedt, 2011), Spatial Principal Component Analysis (SPCA) (Li et al., 2006), Fuzzy Analytic Hierarchy Process (FAHP) (Adriaenssens et al., 2004; Enea and Salemi, 2001; Rahaman et al., 2015) and Artificial Neural-Network (ANN) (Dzeroski, 2001; Park et al., 2004). From which, Analytic Hierarchy Process is utilised for the study to compute the results in a quantitative manner. Analytic Hierarchy Process (AHP) is one of the unique techniques in multiple criteria decision-making approaches. Prominently this semi-arid region requires multi factor to conclude a result, for which pairwise comparison matrix is the best supporting step to assign rank and weightages for each factor so that the hierarchical structure will reflect in the vulnerable

* Corresponding author 
zonation. Especially, the AHP is best suitable for complex criteria in quantitative aspect, where the techniques work as a hierarchical structure in the multiple level of criteria similarly, the study contains Level 1: Eco-environmental vulnerability, Level 2: 4 factors (criteria) and Level 3: 12 sub factors (sub criteria). However, every factor has its part of influencing towards the vulnerability, though in the Pair-wise comparison matrix, the value is determined based on its relative importance compared with one another on their respective target. The highlight of the matrix in each criteria is compared with the rest of the criteria to assign values from the scale of relative importance. Thus, the study preferred AHP as the finest method to adopt for eco-environmental vulnerability assessment. In this present study, Remote sensing data production of Landsat 8 OLI, Sentinel 2B and ALOS PALSAR DEM were incorporated in GIS environment to extract a real-time result. The aim of the study is to evaluate the current eco-environment condition to acquire knowledge about the degree of vulnerability, in order to adopt a management plan for sustainable development in the study area.

\subsection{Objectives}

- The sub factors such as NDMI, NDWI, LST, Rainfall, River proximity, LULC, NDVI, Road proximity, NDBI, Elevation, Aspect and Slope are extracted from appropriate dataset and reclassified through GIS platform.

- Those factors and sub factors are ranked with the criteria weightage $\left(\mathrm{A}_{\mathrm{i}}\right)$ and sub criteria weightage $\left(\mathrm{W}_{\mathrm{i}}\right)$ through pairwise comparison matrix of AHP, in order to obtain four main factors of vulnerability.

- The eco-environmental vulnerability is extracted by integrating the factors of hydro-meteorological, topographical, socio-economical, land resources.

- The vulnerable hotspot is identified from the ecoenvironmental vulnerability for management propose.

\section{STUDY AREA}

\subsection{Regional Setting}

Pombar watershed covers an area of about $1800 \mathrm{~km}^{2}$ and a perimeter around $210 \mathrm{~km}$ with coordinates of $12^{\circ} 42^{\prime} 51^{\prime \prime}$ $12^{\circ} 9^{\prime} 15^{\prime \prime} \mathrm{N}$ latitude and $78^{\circ} 14^{\prime} 55^{\prime \prime}$ - 78 $48^{\circ} 09^{\prime \prime}$ E longitude situated at the northern part of Tamil Nadu, which is positioned in between Krishnagiri and Vellore districts (Figure 1). Which exhibits the annual average temperature of $27.9^{\circ} \mathrm{C}$ and receives an average rainfall of $1002 \mathrm{~mm}$ annually as it falls under the tropical savanna climate (Aw) of Koppen climatic classification. The topographical composition of the watershed ranges from mountain to plain as the Javadhu and Yelagiri hills covering eastern and northwestern part and the rest of the northeastern and southern parts are covered by plateaus and plains respectively. In the watershed, pediplain complex, dissected hills and valleys are the major geomorphic features. The majority area is covered by barren and fallow land, where the cultivable land area remains near to the water bodies and settlements are randomly distributed based on resources. Pombar river flowing in this watershed is a tributary of Thenpennai river. The entire study area encloses three main cities such as Bargur, Thirupattur and Uthangarai, which are well connected with the state highway 179A, these are the major reasons for economic activity along the road and gets it route to neighbouring states and most of the settlements are seen in the foothill regions of Javadhu and Yelagiri hills thus the cultural features persistent in the natural watershed is subjected to eco-environmental vulnerable condition.

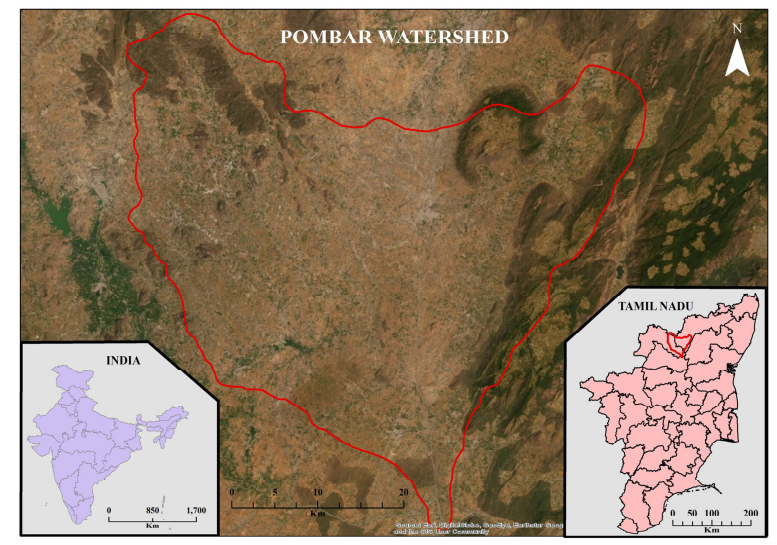

Figure 1. Study area

\section{DATA AND METHODOLOGY}

\subsection{Data Product Utilised}

The data products used for the compilation and generation of the appropriate variables as follows, Landsat 8 OLI for Normalized Difference Moisture Index (NDMI), Normalized Difference Water Index (NDWI), Land Surface Temperature (LST), Normalized Difference Vegetation Index (NDVI) and Normalized Difference Built-up Index (NDBI), the above indices are calculated using the formula shown in Table 1. Accordingly, Sentinel-2B for land use and land cover classification, Advanced Land Observation Satellite-Phased Array type L-band Synthetic Aperture Radar (ALOS PALSAR) DEM for elevation, aspect and slope, IMD rainguage data for rainfall analysis respectively. Both the Landsat 8 OLI and Sentinel-2B utilised for the study is dated in the year 2019. Rainfall is calculated with the average value of 30 years from 1990-2019.

\subsection{Methodology}

The condition of eco-environmental vulnerability will be derived from the major aspects like hydro-meteorology, socio-economic factors, land resources and topography. Thus, the methodology aims to describe the accomplishment and derivation of the result with the spatial content through the remote sensing data products and GIS compilation as described in the figure 2. Each aspect comprises of its own sub factor which is computed to form four major factors and is weighted using the Analytical Hierarchical Process (AHP) for eco-environment vulnerability assessment.

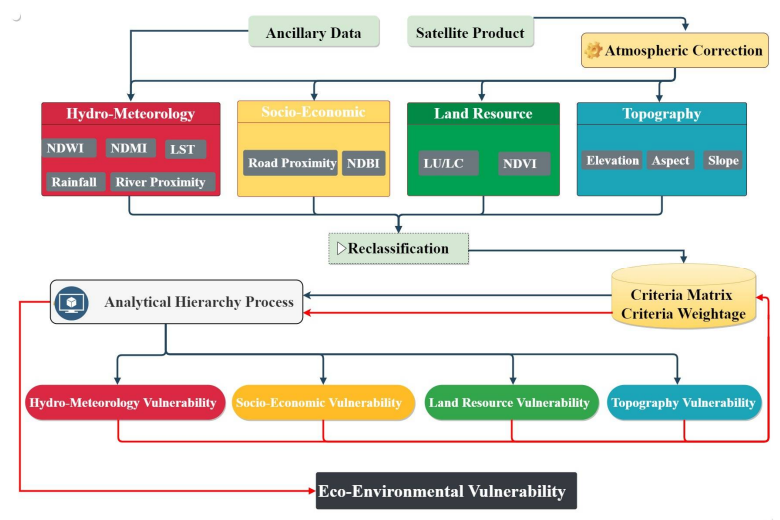

Figure 2. Methodology 
Analytic Hierarchy Process (AHP) is the best decision-making technique in multicriteria evaluation, in this study all the main factors responsible for vulnerability and its sub factors are weighted, ranked and consistency ratio are calculated with the equation developed by (Saaty, 1977, 1980). The factor and sub factors are weighted with the pairwise comparison matrix (Saaty, 1990, 1994; Saaty and Vargas, 2001; Rahaman and Aruchamy, 2017; Nitheshnirmal et al., 2018), each factor is compared with another factor to assign a value based on their importance from the scale of 1 to 9 . Then 1 is equalizing importance, 9 is for extreme importance and so on. In pairwise comparison matrix, the consistency of matrix is checked with consistency ratio (CR), which is calculated by ratio of consistency index $(\mathrm{CI})$ and average random consistency index (RI), the RI is constant value created by (Saaty, 1980). Those values of CR should be less than 0.01 or else the matrix must reform or reject; in this study the calculated $\mathrm{CR}$ is 0.054 . Therefore, the matrix is consistent for proceeding with subsequent steps. The CR and CI is calculated with the formula mentioned in the equation 1 and 2 .

$$
\begin{aligned}
& \mathrm{CR}=\frac{\mathrm{CI}}{\mathrm{RI}} \ldots \\
& \mathrm{CI}=\frac{\lambda_{\max }-\mathrm{n}}{\mathrm{n}-1}
\end{aligned}
$$

Where, $\lambda \max$ is Principal Eigen Value of the matrix and $n$ is an order of the matrix. Furthermore, the Eco-environment Vulnerability Index (EVI) is calculated using the following equation (3).

$$
\mathrm{EVI}=\sum\left(\mathrm{A}_{1} * \mathrm{~W}_{1}+\mathrm{A}_{2} * \mathrm{~W}_{2}+\mathrm{A}_{3} * \mathrm{~W}_{3}+\mathrm{A}_{4} * \mathrm{~W}_{4}\right) \ldots .
$$

\begin{tabular}{lcc}
\hline Indices & Formula & Reference \\
\hline NDBI & $N D B I=\frac{(S W I R 2-N I R)}{(S W I R 2+N I R)}$ & $\begin{array}{c}\text { (Zha et al., } \\
2003 ; \text { Sharma } \\
\text { et al., 2013) }\end{array}$ \\
\hline NDVI & $N D V I=\frac{(N I R-R E D)}{(N I R+R E D)}$ & $\begin{array}{c}\text { Farrar, 1994; } \\
\text { Vicente- } \\
\text { Serrano, } \\
2007)\end{array}$ \\
\hline NDMI & $N D M I=\frac{(N I R-I R)}{(N I R+I R)}$ & $\begin{array}{c}(\text { Jin and } \\
\text { Sader, 2005) }\end{array}$ \\
\hline NDWI & $N D W I=\frac{(N I R-G)}{(N I R+G)}$ & $\begin{array}{c}\text { (Wu et al, } \\
2009 ; \\
\text { Jackson,2004) }\end{array}$ \\
\hline
\end{tabular}

$$
\begin{aligned}
& \text { 1. Digital Numbers to spectral } \\
& \text { radiance } \\
& \mathrm{L} \lambda=\mathrm{ML} * \mathrm{Qcal}+\mathrm{AL} \\
& \text { 2. Spectral radiance to } \\
& \text { brightness temperature } \\
& \mathrm{BT}=\mathrm{K} 2 / \ln (\mathrm{k} 1 / \mathrm{L} \lambda+1)- \\
& 273.15 \\
& P V\left\{\frac{\mathrm{NDVI}-\mathrm{NDVI}_{\min }}{\mathrm{NDVI}_{\max }-\mathrm{NDVI}_{\text {Min }}}\right\}^{2} \\
& \text { 4. Land Surface Emissivity } \\
& \mathrm{LSE}=0.004 * \mathrm{PV}+0.986 \\
& \text { 5. Land Surface Temperature } \\
& \mathrm{LST}=(\mathrm{BT} / 1)+\mathrm{W} *(\mathrm{BT} / \\
& 14380) * \ln (\mathrm{LSE})
\end{aligned}
$$

\begin{tabular}{|c|c|c|c|}
\hline $\begin{array}{l}\text { Main } \\
\text { Factor }\end{array}$ & $\begin{array}{c}\text { Criteria } \\
\text { Weight } \\
\left(\mathbf{A}_{\mathbf{i}}\right)\end{array}$ & $\begin{array}{c}\text { Sub Factors } \\
\left(\mathbf{B}_{\mathbf{i}}\right)\end{array}$ & $\begin{array}{l}\text { Sub Criteria } \\
\text { Weight }\left(\mathbf{W}_{\mathrm{i}}\right)\end{array}$ \\
\hline \multirow{5}{*}{$\begin{array}{c}\text { Hydro } \\
\text { Meteorology } \\
\left(A_{1}\right)\end{array}$} & \multirow{5}{*}{0.197} & $\operatorname{NDMI}\left(\mathrm{B}_{1}\right)$ & 0.248 \\
\hline & & $\operatorname{NDWI}\left(\mathrm{B}_{2}\right)$ & 0.058 \\
\hline & & $\operatorname{LST}\left(\mathrm{B}_{3}\right)$ & 0.121 \\
\hline & & Rainfall (B4) & 0.487 \\
\hline & & $\begin{array}{c}\text { River } \\
\text { Proximity }\left(\mathrm{B}_{5}\right)\end{array}$ & 0.086 \\
\hline \multirow{2}{*}{$\begin{array}{c}\text { Land } \\
\text { Resources } \\
\left(\mathrm{A}_{2}\right)\end{array}$} & \multirow{2}{*}{0.321} & $\begin{array}{c}\text { Road } \\
\text { Proximity }\left(\mathrm{B}_{6}\right)\end{array}$ & 0.546 \\
\hline & & $\operatorname{NDBI}\left(B_{7}\right)$ & 0.454 \\
\hline \multirow{2}{*}{$\begin{array}{l}\text { Topography } \\
\qquad\left(\mathrm{A}_{3}\right)\end{array}$} & \multirow{2}{*}{0.151} & LU\LC (B8) & 0.578 \\
\hline & & NDVI (B9) & 0.422 \\
\hline \multirow{3}{*}{$\begin{array}{l}\text { Socio- } \\
\text { Economic } \\
\left(\mathrm{A}_{4}\right)\end{array}$} & \multirow{3}{*}{0.331} & Elevation $\left(\mathrm{B}_{10}\right)$ & 0.565 \\
\hline & & Aspect $\left(B_{11}\right)$ & 0.317 \\
\hline & & Slope $\left(B_{12}\right)$ & 0.118 \\
\hline
\end{tabular}$$
\text { LST 3. Proportion of Vegetation }
$$

Table 1: Formula for calculating Remote Sensing Indices

\begin{tabular}{c|c|c|c|c}
\hline Factors & $\mathbf{A}_{\mathbf{1}}$ & $\mathbf{A}_{\mathbf{2}}$ & $\mathbf{A}_{\mathbf{3}}$ & $\mathbf{A}_{\mathbf{4}}$ \\
\hline $\mathbf{A}_{\mathbf{1}}$ & 1 & $1 / 2$ & 3 & $1 / 3$ \\
$\mathbf{A}_{\mathbf{2}}$ & 2 & 1 & 3 & 2 \\
$\mathbf{A}_{\mathbf{3}}$ & $1 / 3$ & $1 / 3$ & 1 & $1 / 3$ \\
$\mathbf{A}_{\mathbf{4}}$ & 3 & $1 / 2$ & 3 & 1 \\
\hline
\end{tabular}

Table 2: Pairwise Comparison Matrix with respect to Ecoenvironment Vulnerability

*Hydro-Meteorology $\left(A_{1}\right)$, Land Resources $\left(A_{2}\right)$, Topography $\left(A_{3}\right)$, Socio-Economic $\left(A_{4}\right)$

The Remote Sensing indices used in the study were calculated using the formula shown in table 1. After extraction of required sub factors from an appropriate dataset, those factors were reclassified with reference to vulnerability scale. Using pairwise comparison matrix as displayed in table 2 , the criteria and sub criteria weightage (table 3 ) have been calculated with AHP techniques. Using Raster calculator in ArcGIS 10.1 to identify the eco-environment vulnerability with the equation (3).

Table 3: Weightage for Factors and Sub factors

\section{RESULT AND DISCUSSION}

\subsection{Spatial Distribution of Vulnerability Factors}

Eco-environmental vulnerability mapping helps to spot the potential hazardous zone to protect and preserve the environmental resources and to implement the developmental planning by using the framed methodology in the above section. Eco-environmental vulnerability is based on four factors such as hydro-meteorological, topographical, socio-economical, land resources. Each factor has its specific sub factors, which will contribute to the vulnerability. Then combined impact of factors used to generate the eco-environmental vulnerability. Those four 
factors responsible for eco-environmental vulnerability are extracted from its own sub factors and spatially distributed within five classes (very high, high, moderate, low and very low) based on natural interval classification method (de Smith et al., 2015).

\subsubsection{Hydro-Meteorological Vulnerability}

Hydro-Meteorology is a concept of estimating the precipitation and water availability related components. Where it is embraced by NDMI, NDWI, LST, Rainfall and River proximity. These components are interrelated with one another and has an adverse effect on the prevailing condition of the water availability. Where it expresses the proportionality of the contribution towards the risk of hydro-meteorology conditions. The result of hydrometeorology vulnerability as shown in the figure 3 , where the observed five major zones range from very high to very low vulnerability. NDWI, LST, rainfall and river proximity have a positive relationship with the hydro-meteorological vulnerability, on the other hand, NDMI has a negative. The North-western part of the study area is the most vulnerable part due to the high rainfall and adequate surface temperature that is directly proportional to the human habitat that influences the region in the most vulnerable zone. It covers almost $18 \%$ of the area. A $53 \%$ of the area covers under low and very low vulnerability, especially in the hilly terrain the vulnerability is very low due to low human intervention.

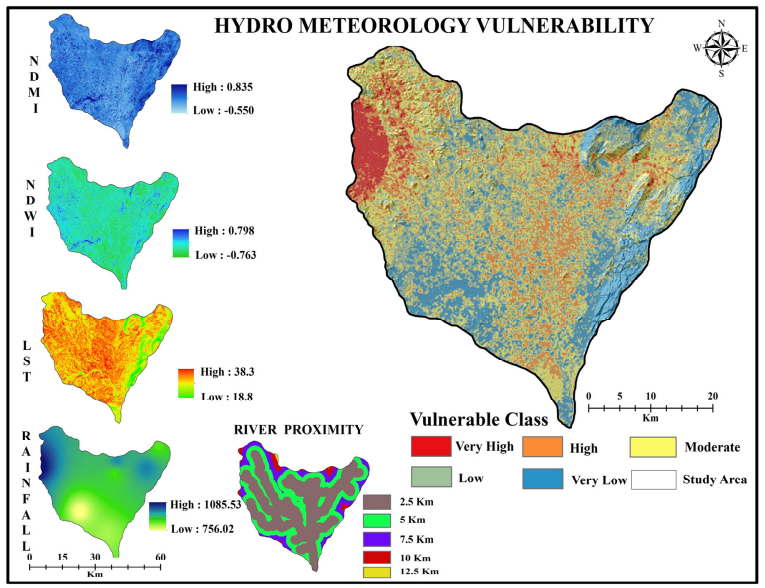

Figure 3. Hydro-Meteorological Vulnerability

\subsubsection{Land Resource Vulnerability}

Land Resources will always tend to evaluate the condition of the land and the presence of vegetation throughout the study sites. In which LULC and NDVI were utilised. Here the LULC is used to know the prevailing land use pattern and the NDVI for showing the vegetation stress and its spatial distribution, which was combined to estimate the land resources vulnerability. The final result of the land resource vulnerability map portrayed as in the figure 4 . In north-eastern part, $24 \%$ of the study area fall under moderate to low vulnerability and there is an absence of very low vulnerability. Almost $71 \%$ of the area is under very high to high vulnerability. There are five major zones like hydro-meteorology vulnerability, NDVI clearly shows that the highly vegetated areas have less land resource vulnerability compared to the low vegetated area. Land use/land cover also has a greater influence on land resource vulnerability, fallow land and barren land also depict the land as most vulnerable.

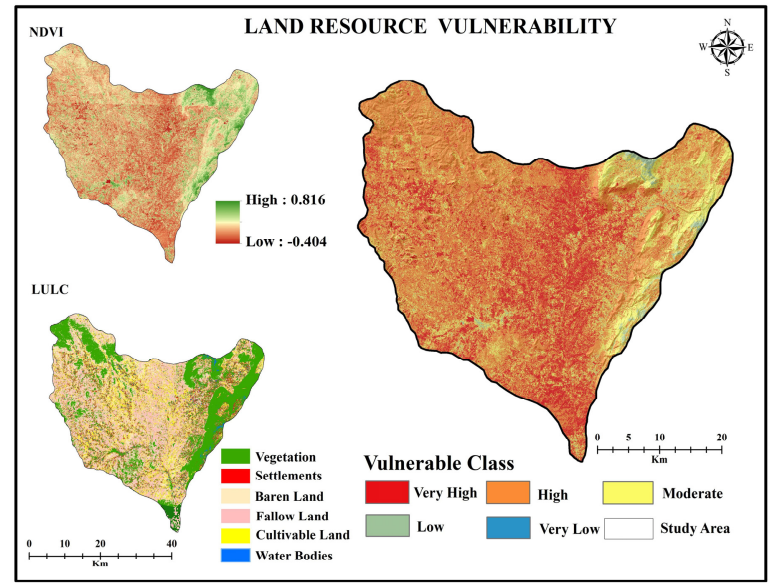

Figure 4. Land Resources Vulnerability

\subsubsection{Socio-Economic Vulnerability}

Socio-Economic condition is a factor which shows the nature of the cultural feature affecting the existing natural environment. For which road proximity and NDBI has been obtained. This will render the economic impact of the highways passing through the study sites. The locations and spatial distribution of built-up area are more important in the vulnerability assessment. Road proximity is inversely proportionate to the socio-economic vulnerability, on the other hand, the NDBI is directly related to socio-economic vulnerability. Road proximity clearly shows that areas near the road have high vulnerability compared to other areas. And the NDBI clarifies that the low built-up areas have low vulnerability and high built up have a high vulnerability. The final map (figure 5) shows the socio-economic vulnerability and the influence of road and built up very clearly. Nearly $31 \%$ of the area has low to moderate vulnerability and $58 \%$ of area has very high to high vulnerability.

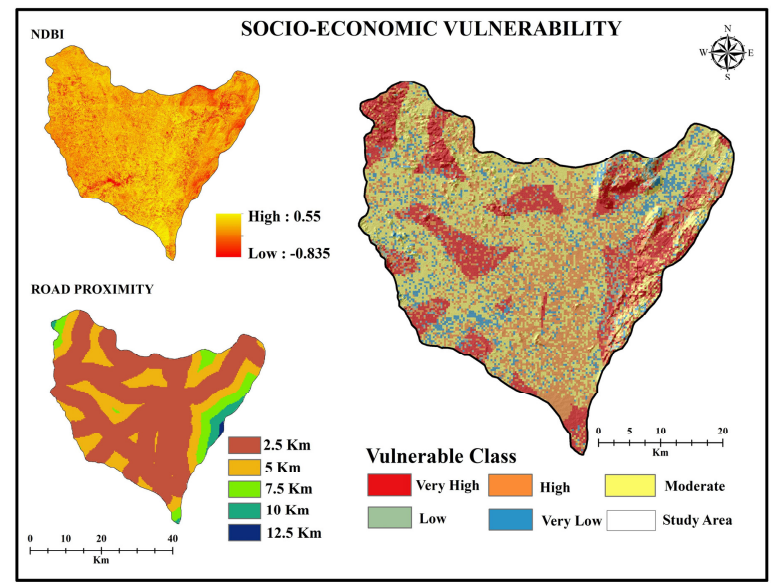

Figure 5. Socio-Economic Vulnerability

\subsubsection{Topographical Vulnerability}

Topography is one of the main aspects which reflects the exact environmental and natural anomaly of the surface. Elevation, aspect and slope are those sub factors taken into consideration for evaluating topography. This will reflect the natural condition of the watershed in the perspectives of a topographical point of 
view. The map of the topography vulnerable zone is displayed in the figure 6. Elevation has direct influence on topographical vulnerability, in higher elevated areas the topographic vulnerability is less compared to the plain areas. The slope angle and slope aspect also have their respective influence on the topography vulnerability. Most of the area $(62 \%)$ especially the central and southern part covered with very high vulnerability. The eastern part of the study area covered with low to very low vulnerability, all other areas almost covered with very high to high vulnerability.

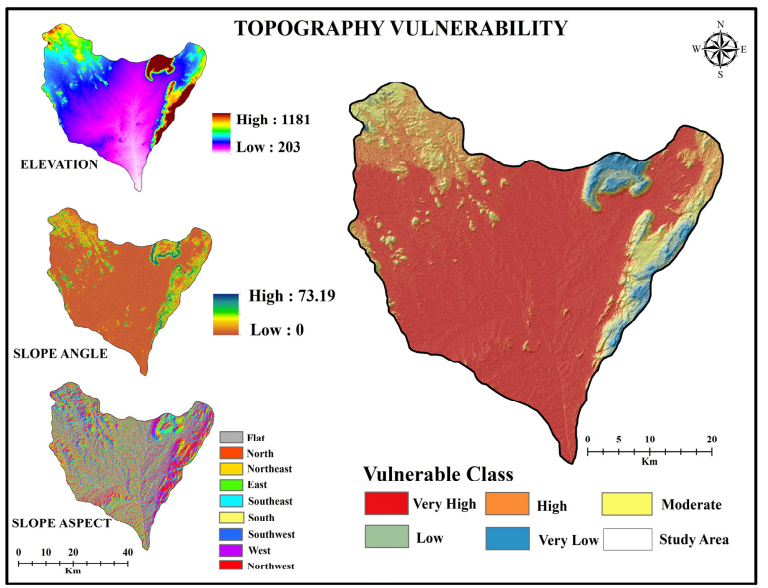

Figure 6. Topography Vulnerability

\subsection{Eco-Environmental Vulnerability Assessment}

The spatial distribution of eco-environmental vulnerability (figure 7) has five classes, (very high, high, moderate, low and very low), Topographical factor plays a major role in distribution of vulnerability, in higher elevation less vulnerable and viceversa. The very high vulnerability class is randomly distributed, especially in the foothill region, western and southern tip of the study area, those regions are affected by both nature (drought) and anthropogenic activities (urbanisation, industrialisation, migration and economic activities). High vulnerability is distributed in flat region of entire watershed, those regions are prone to steady degradation, and more human interventions. Moderate vulnerability class is marked out in the north-western and central part, the region has moderate degree of vulnerability due to less socio-economic activities. Low vulnerability is sparsely distributed in the plateau region with very low level of human activities because in the plateau region habitation will be lower due to its physiographic and climatic conditions. And the very low vulnerability class is located in elevated regions, where region is free from urbanisation, industrialisation, so that it can hold potential resources and away from the degradation, pollution, drought and so on.

\subsection{Focus Region on Eco-Environmental Vulnerability}

The outcome of the assessment framework delivers a realistic output to identify a vulnerable zone and to propose management planning for development of the study area. For this concern, the vulnerability classes were clubbed into three categories of management. The first category is a combination of very high and high vulnerable class, the region with a high level of urbanisation and industrialisation, economic activities and natural calamities, so it requires an instantaneous management for restoring and developmental strategies, Second category is moderate vulnerable class, the region need a steady level of protection and management plan because the degree of vulnerability will be restored naturally in some instances like excess precipitation. The low and very low vulnerable class were merged to form the third category, here the gradual controlling measure can be followed, because the environment declining will be very low or zero at certain times.

In terms of protection, three zones are identified as shown in the figure 8 . Zone 1 is situated in western side, the zone engaged with enormous settlements, thus the region is ecologically down. 80 percentage of vegetation is washed out due to over-exploitation of surface and sub-surface water. Zone 2 is a foothill region with dominant levels of deforestation, pollution and tertiary activities is leading in order to extract a forest resource. Zone 3 is located in the southern gradient of a watershed, the zone of river interconnection. In this zone, vegetation and soil around the river are totally eroded and degraded, due to excessive utilisation of river and its adjacency. The eco-environmental vulnerability in the study area has been studied in physical dimension regionally and further, there is a need to segregate them based on the administrative division for effective planning. And in vulnerability map three zones are identified, those zones were under a most hazardous condition so that the immediate response and restoration process must be executed to resist the resources left over, rebuild the degraded eco-environment and absolute planning and management methods should be considered.

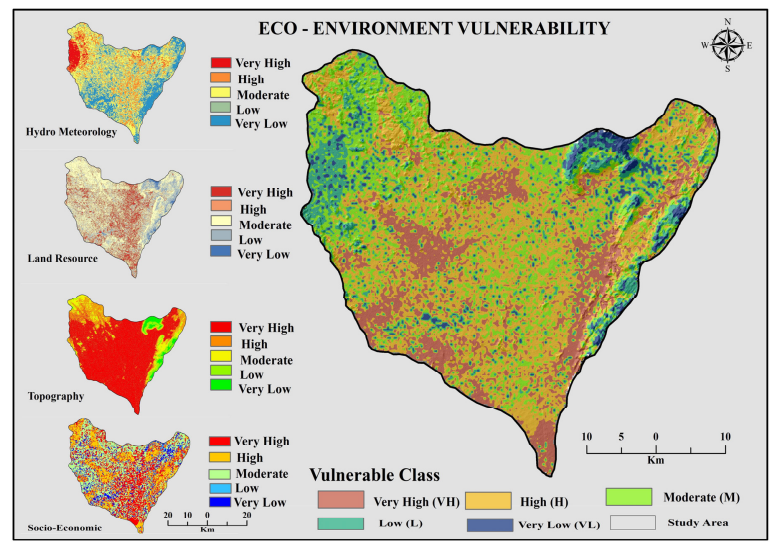

Figure 7. Spatial Distribution of Eco-Environmental Vulnerability

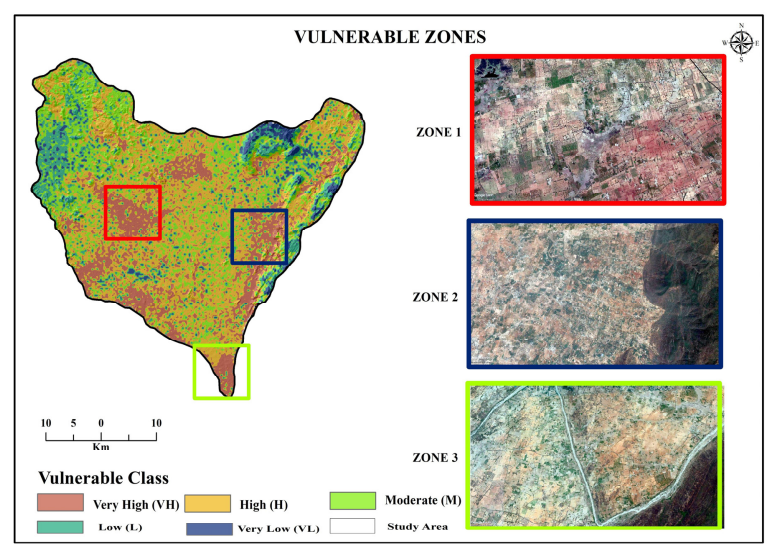

Figure 8. Hot Spot Zonation of Eco-Environmental Vulnerability 


\section{CONCLUSION}

The integrated approaches of Geospatial technology with AHP is effectively used to extract an eco-environment vulnerability zone in Pombar watershed. A quantitative method of AHP is optimally applied to all the influencing factors and sub-factors for real-time results. Those results were verified and examined with decision and policymakers to get the suggestion and to state a suitable protection and management techniques. Every individual in the Pombar watershed should require the knowledge and information to get exposure over eco-environmental balance and relationship between nature and human. Thus, urge the need to assess the ecoenvironmental vulnerability in the study area. The results clearly depict that overall watershed is under moderate vulnerability class. In watershed, low lying plain regions are mostly affected by natural and anthropogenic activities, which falls under very high and high vulnerable class. These regions necessitate for immediate action against environmental degradation such as reforestation of trees, adding an artificial soil nutrient, minimalize the tertiary activities in the core regions. And the low and very low vulnerable class are lying in the elevated regions, here the ecological balance will be in an equilibrium state, though the degradation happens it will get restored on its own. Then, moderate vulnerable zone is distributed in the plateau region. In this region, declining of the environment is proceeded in a moderate scale, so in plateau region the measures like afforestation, step cultivation, multi-cropping should be practised to hold the soil stability. And various management measures like spreading awareness about the eco-environment vulnerability to local level, optimal uses of land and water resources, terrace cultivation, maintaining an urban heat island, and adopting a lifestyle towards sustainable development.

\section{ACKNOWLEDGEMENT}

I would like to express my heartfelt gratitude to the Department of Geography, Bharathidasan University for letting to utilise the lab facilities. And special thanks to anonymous reviewers for their valuable comments to improve the quality of manuscript.

\section{REFERENCES}

Adriaenssens, V., De Baets, B., Goethals, L. M. P., De Pauwa, N., 2004: Fuzzy rule-based models for decision support in ecosystem management. Science Total Environment., 319, 1-12, https://doi.org/10.1016/S0048-9697(03)00433-9.

Artis, D. A., Carnahan, W. H., 1982: Survey of emissivity variability in thermography of urban areas. Remote Sensing of Environment., 12, 313-329, https://doi.org/10.1016/00344257(82)90043-8.

Belal, A., El-Ramady, H. R., Mohamed, E.S., Saleh M.A., 2014: Drought risk assessment using remote sensing and GIS techniques. Arabian Journal of Geosciences., 7, 35-53 https://doi.org/10.1007/s12517-012-0707-2.

Chander, G., Markham, B.L., Helder, D.L., 2009: Summary of current radiometric calibration coefficients for Landsat MSS, TM, ETM+ and EO-1 ALI sensors. Remote Sensing of Environment., 113, 893-903. https://doi.org/10.1016/j.rse.2009.01.007.

Wang, D., Zhong, X.H., Liu, S.Z., Liu, J.G., Wang, Z.Y., Li., M.H., 2008: Regional assessment of environmental vulnerability in the Tibetan Plateau: Development and application of a new method. Journal of Arid Environments., 72(10), 1929-1939. https://doi.org/10.1016/j.jaridenv.2008.06.005. de Smith, M., Goodchild, M.F., Longley, P.A., 2015. Geospatial Analysis, 5th Edition. The Winchelsea Press, Winchelsea, UK.
Dutta, D., Kundu, A., Patel, N.R., Saha, S.K., Siddiqui, A. R., 2015: Assessment of agricultural drought in Rajasthan (India) using remote sensing derived Vegetation Condition Index (VCI) and Standardized Precipitation Index (SPI). The Egyptian Journal of Remote Sensing and Space Science., 18(1), 53-63, https://doi.org/10.1016/j.ejrs.2015.03.006.

Dzeroski, S., 2001: Applications of symbolic machine learning to ecological. Ecological Modelling., 146, 263-273, https://doi.org/10.1016/S0304-3800(01)00312-X.

El Baroudy, A. A., 2011: Monitoring land degradation using remote sensing and GIS techniques in an area of the middle Nile Delta, Egypt. Catena., 87(2), 201-208. https://doi.org/10.1016/j.catena.2011.05.023.

Enea, M., Salemi, G., 2001: Fuzzy approach to the environmental impact evaluation. Ecological Modelling. 135, 131-147, https://doi.org/10.1016/S0304-3800(00)00380-X.

Farrar, T.J., Nicholson, S.E., Lare, A.R., 1994: The influence of soil type on the relationships between NDVI, rainfall, and soil moisture in semiarid Botswana. II. NDVI response to soil moisture. Remote Sensing of Environment, 50 (2),121-133. https://doi.org/10.1016/0034-4257(94)90039-6.

Goda, T., Matsuoka, Y., 1986: Synthesis and analysis of a comprehensive lake model - with the evaluation of diversity of ecosystem. Ecological Modelling., 31 (1-4), 11-32, https://doi.org/10.1016/0304-3800(86)90052-9.

Guebas, F, D., 2002: The Use of Remote Sensing and GIS in the Sustainable Management of Tropical Coastal Ecosystems. Environment, Development and Sustainability. 4, 93-112.

https://doi.org/10.1023/A:1020887204285.

Gustafson, E., Hammer, R., Radeloff, V., Potts, R. 2005: The Relationship between Environmental Amenities and Changing Human Settlement Patterns between 1980 and 2000 in the Midwestern USA. Landscape Ecology., 20, 773-789, https://doi.org/10.1007/s10980-005-2149-7.

Jackson, T.J., Chen, D., Cosh, M., Li, F., Anderson, M., Walthall, C., Doriaswamya, P., Hunt, E.R., 2004: Vegetation water content mapping using Landsat data derived normalized difference water index for corn and soybeans. Remote Sensing of Environment., 92, 475-482. https://doi.org/10.1016/j.rse.2003.10.021.

Jin, S., and Sader, S.A., 2005: Comparison of time series tasseled cap wetness and the normalized difference moisture index in detecting forest disturbances. Remote Sensing of Environment., 94 (3), 364-372. https://doi.org/10.1016/j.rse.2004.10.012.

Bahadur, K. C. K., 2009: Mapping soil erosion susceptibility using remote sensing and GIS: a case of the Upper Nam Wa Watershed, Nan Province, Thailand. Environmental Geology., 57, 695-705, https://doi.org/10.1007/s00254-0081348-3

Krivtsov, V., 2004: Investigations of indirect relationships in ecology and environmental sciences: a review and the implications for comparative theoretical ecosystem analysis. Ecological Modelling., $\quad 174, \quad 37-54$. https://doi.org/10.1016/j.ecolmodel.2003.12.042.

Li, A., Wang, A., Liang, S., and Zhou, W. 2006: Ecoenvironmental vulnerability evaluation in mountainous region using remote sensing and GIS-A case study in the upper reaches of Minjiang River, China. Ecological Modelling., 192 (1-2), 175187. https://doi.org/10.1016/j.ecolmodel.2005.07.005.

Liou, Y.A., Nguyen, A.K., and Li, M.H., 2017: Assessing spatiotemporal eco-environmental vulnerability by Landsat data, Ecological Indicators., $\quad 80, \quad 52-65$, https://doi.org/10.1016/j.ecolind.2017.04.055.

MacMillan, R.A., Jones, R.K., McNabb, D.H., 2004: Defining a hierarchy of spatial entities for environmental analysis and modeling using digital elevation models (DEMs). Computers, 
Environment and Urban Systems., 28, 175-200. https://doi.org/10.1016/S0198-9715(03)00019-X.

Nguyen, A.K., Liou, Y.A., Li, M.H., and Tran, T.A. 2016: zoning eco-environmental vulnerability for environmental management and protection. Ecological Indicators., 69, 100-117, https://doi.org/10.1016/j.ecolind.2016.03.026.

Nitheshnirmal, S., Thilagaraj, P., Abdul Rahaman, S., Jegankumar, R., 2019: Erosion risk assessment through morphometric indices for prioritisation of Arjuna watershed using ALOS-PALSAR DEM. Modeling Earth Systems and Environment 5:1-18. https://doi.org/10.1007/s40808-019-00578y.

Nitheshnirmal, S., Rahaman, S. A., Balasundareshwaran, A., Nivedita Priyadarshini, K., Balasubramani, K., Kumaraswamy, K. 2018: Spatio-Temporal Analysis of Natural Human Habitability Environment along The Coastal Taluks of Tamil Nadu, India, ISPRS Annals Photogrammetry Remote Sensing. Spatial Inf. Sci., IV-5, 439-446, https://doi.org/10.5194/isprsannals-IV-5-439-2018, 2018.

Park, Y.S., Chon, T.S., Kwak, I.S., and Iek. S. 2004: Hierarchical community classification and assessment of aquatic ecosystems using artificial neural networks. Science of the Total Environment., 327, 105-122, https://doi.org/10.1016/j.scitotenv.2004.01.014.

Pradhan, B., Chaudhari, A., Adinarayana, J., Buchroithner, M.F. 2012: Soil erosion assessment and its correlation with landslide events using remote sensing data and GIS: a case study at Penang Island, Malaysia. Environmental Monitoring and Assessment., 184, 715-727. https://doi.org/10.1007/s10661011-1996-8.

Rahaman, S. A., Aruchamy, S., Jegankumar, R., Ajeez, S. A. 2015: Prioritization of Sub Watershed Based on Morphometric Characteristics Using Fuzzy Analytical Hierarchy Process and Geographical Information System - A Study of Kallar Watershed, Tamil Nadu. International conference on water resources, coastal and ocean engineering (icwrcoe 2015). $\begin{array}{llll}\text { Aquatic } & \text { Procedia } & 4: 1322 & -1330 .\end{array}$ https://doi.org/10.1016/j.aqpro.2015.02.172.

Rahaman, S.A., Aruchamy, S. 2017: Geoinformatics based landslide vulnerable zonation mapping using analytical hierarchy process (AHP), a study of Kallar River sub watershed, Kallar watershed, Bhavani Basin, Tamil Nadu. Springer International Publishing Switzerland Modeling Earth Systems and Environment, 3(41), 1-13. https://doi.org/10.1007/s40808-0170298-8.

Rigina, O., 2002: Environmental Impact Assessment of the Mining and Concentration Activities in the Kola Peninsula, Russia by Multidate Remote Sensing. Environmental Monitoring and Assessment., 75, 13-33. https://doi.org/10.1023/A:1014248522919.

Saaty, T. L., 1977: A scaling method for priorities in Hierarchial structures. Journal of Mathematical Psychology., 15(3), 234 281. https://doi.org/10.1016/0022-2496(77)90033-5.

Saaty, T. L. 1980. The Analytical Hierarchy Process. McGraw Hill, New York.

Saaty, T. L. 1990. The Analytic Hierarchy Process: Planning, Priority Setting, Resource Allocation, first ed. RWS Publications, Pittsburgh, p. 502.

Saaty, T.L. 1994. Fundamentals of Decision Making and Priority Theory with Analytic Hierarchy Process, first ed.RWS Publications, Pittsburgh, p. 527.

Saaty, T.L., and Vargas, L.G. 2001. Models, Methods, Concepts, and Applications of the Analytic Hierarchy Process,1st ed. Kluwer Academic, Boston, p. 333. DOI: 10.1007/978-1-46143597-6.

Sharma, R., Ghosh, A., and Joshi, P.K. 2013: Spatio-temporal footprints of urbanisation in Surat, the Diamond City of India
(1990-2009). Environmental Monitoring and Assessment.,185, 3313-3325. https://doi.org/10.1007/s10661-012-2792-9.

Sobrino, J.A., Jimenez-Munoz, J.C., and Paolini, L., 2004: Land surface temperature retrieval from Landsat TM 5. Remote Sensing of Environment., 90, 434-440. https://doi.org/10.1016/j.rse.2004.02.003.

Song, G., Chen, Y., Tian, M., Lv, S., Zhang, S., Liu, S., 2010: The ecological vulnerability evaluation in Southwestern Mountain Region of China based on GIS and AHP method. Procedia Environmental Sciences., 2, 465-475. https://doi.org/10.1016/j.proenv.2010.10.051.

Store, R., Jokima“ki, J., 2003: A GIS-based multi-scale approach to habitat suitability modeling. Ecological Modelling., 169, 1-15. https://doi.org/10.1016/S0304-3800(03)00203-5.

Thanh, L.N., De Smedt, F., 2011: Application of an analytical hierarchical process approach for landslide susceptibility mapping in A Luoi district, Thua Thien-Hue Province, Vietnam. Environmental Earth Sciences., 66 (7), 1739-1752. https://doi.org/10.1007/s12665-011-1397-x.

Valor, E., Caselles, V., 1996: Mapping land surface emissivity from NDVI: application to European, African, and South American areas. Remote Sensing of Environment., 57,167-184, https://doi.org/10.1016/0034-4257(96)00039-9.

Vicente-Serrano, S.M., 2007: Evaluating the Impact of Drought Using Remote Sensing in a Mediterranean, Semi-arid Region. Natural Hazards., 40, 173-208, https://doi.org/10.1007/s11069006-0009-7.

Weston, J., 2004: EIA in a risk society. Journal of Environmental Planning and Management., 47, 313-325, https://doi.org/10.1080/0964056042000209058.

Wu, C., Niu, Z., Tang, Q., Huang.W., 2009: Predicting vegetation water content in wheat using normalized difference water indices derived from ground measurements. Journal of Plant Research.,122, 317-326, https://doi.org/10.1007/s10265009-0215-y.

Zha, Y., Gao, J., Ni, S., 2003: Use of normalized difference builtup index in automatically mapping urban areas from TM imagery. International Journal of Remote Sensing., 24 (3),583594, https://doi.org/10.1080/01431160304987. 